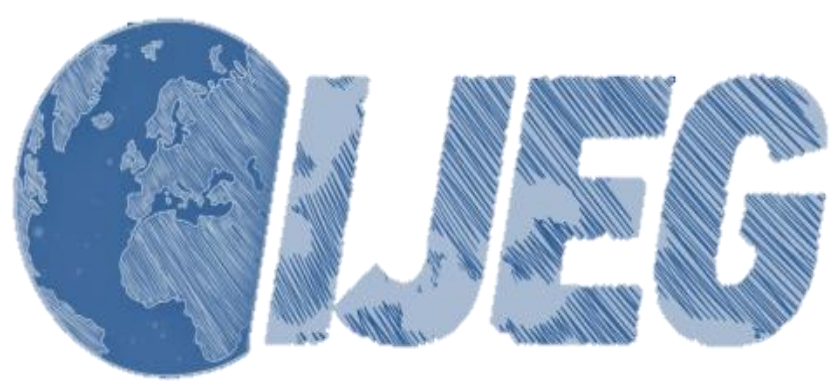

International Journal of Engineering and Geosciences (IJEG),

Vol; 5, Issue; 1, pp. 049-059, February, 2020, ISSN 2548-0960, Turkey,

DOI: 10.26833 ijeg. 581584

\title{
INTERPRETING DEFORMATION RESULTS OF GEODETIC NETWORK POINTS USING THE STRAIN MODELS BASED ON DIFFERENT ESTIMATION METHODS
}

\author{
Haluk Konak $^{1^{*}}$, Pakize Küreç Nehbit ${ }^{2}$, Aslıhan karaöz ${ }^{1}$, Fazilet Cerit ${ }^{1}$ \\ ${ }^{1}$ Kocaeli University, Institutes of Natural and Sciences, Department of Geodesy and Geoinformation, Kocaeli, Turkey \\ (hkonak@kocaeli.edu.tr, karaozaslhan@ gmail.com, fazilet.cerit2010@ gmail.com); ORCID 0000-0003-2554-8905, \\ ORCID 0000-0003-2371-8958, ORCID 0000-0002-0524-4237 \\ ${ }^{2}$ Kocaeli University, Engineering Faculty, Department of Geodesy and Geoinformation, Kocaeli, Turkey \\ (pkurec80@yahoo.com); ORCID 0000-0003-2669-0401
}

*Corresponding Author, Received: 24/06/2019, Accepted: 02/09/2019

\begin{abstract}
Geodetic Networks designed as Deformation Networks or Continuous Networks are observed in different epochs/ sessions and evaluated as a function of time. Those can be design as global GNSS networks for aim monitoring active tectonic movements or as regional densification geodetic and deformation networks for monitoring local earthquakes and surface movements. The areas covered geodetic networks are assumed as any surface on ellipsoid or sphere. Characteristics of surfaces are analyzed with Geometric Strain Models using deformation data on surface points. In this case, effect rates on geodetic network area are determined from local surface movements or regional active earthquakes and interpreted as experimental. On the other hand, undetermined outliers by model hypothesis test affect coordinateunknowns separately. Outliers cause deformations in certain magnitude on networks points. Therefore, network points strain in different rates and directions. Query of maximum affects caused by these strain rates is a referenced reliability method called "Robustness Analysis in Geodetic Networks". Mentioned strain rates are modelled by various estimation methods. Thus, deformation results could be interpreted together by the obtained strain components and deformation vector.

In this paper, possible strain components belonging to network points are determined with methods of L1 Norm, Least Median Squares (LMS) and Least Squares Estimation (LSE). These estimation methods are tested on KOUSAGA (Kocaeli University Permanent GPS Network). Strain components are estimated by use polyhedrons covered by network points. Obtained results are compared and analyzed according to weakness and strengths of proposed estimation methods.
\end{abstract}




\section{INTRODUCTION}

Geodetic networks can be designed in different shape and sizes according to their functions and purpose as global, regional or local. Point-position coordinates of these networks can be defined using geocentric or local coordinate systems and then evaluated together with classical and satellite-based observations. Geodetic networks can be continuously measured by advanced satellite measurement techniques in different epochs and sessions, and evaluated with appropriate mathematical statistics methods; their geometric structures and pointpositions can be monitored periodically. Accordingly, in areas covered by geodetic networks, possible tectonic plate deformations, crustal movements, large and important engineering infrastructures and time-dependent regular periodic changes in their environment can be modeled and possible local-block movements can be detected. The areas covered by geodetic networks are assumed as any surface on ellipsoid or sphere. The displacement ratios of the network points on this surface have deformation and strain information representing the surface. Surfaces characteristics are analyzed with geometric strain models using deformation data on surface points, in any coordinate system and datum free. As a result of this situation, affect rates of the areas covered by geodetic networks from local surface movements or regional active earthquakes are determined and interpreted as experimental.

On the other hand, undetermined outliers by model hypothesis test affect coordinate-unknowns separately. Outliers cause deformations in certain magnitude on network points and these points strain in different rates and directions. Query of maximum affects caused by these strain rates is a referenced reliability method called "Robustness Analysis in Geodetic Networks". A priori or a posteriori strain rates are modelled by various estimation methods. Thus, deformation results could be interpreted together by the obtained strain components and deformation vectors.

Possible strain components belonging to network points on the any surface are determined with different estimation methods. Depending on the nature of the surface movements, the strain components related to any surface can be modeled and interpreted by geometric, geodetic and/or geophysical data. The estimates that having minimum variance, consistently, efficiently, sufficiently and at least asymptotically unbiased should be used for the strain models. In this study, the possible strain in the network points is determined by Least Absolute Value (LAVM, L1-Norm), Least Median Squares (LMS) and Least Squares (LS, L2-Norm) estimation methods.

In an estimation process; it is aimed to obtain the most consistent unknown parameters and the measurement corrections having the greatest probability without removing any measurements (Öztürk and Şerbetçi, 1992). The LAV estimation method is a Maximum Likelihood Estimation (MLE) method, which minimizes the sum of absolute values of corrections by using any combinations of measurements as many as the unknown parameters number. With LAV method, it is aimed to minimize the effect of the data in contradiction with normal distribution. This objective function cannot always be guaranteed by the LAV methods. In this case, LMS method is recommended as another MLE method which controls the LAV method (Niemeier, 2002).

The MLE method gives successful results when the distribution of measurements is well known. On the other hand, LS estimation method provides minimum variance and unbiased results for the sets of measures which are known to have normal distribution at the beginning or not. However, the LS method can spread the effects of possible outliers with higher weights to the other observations (Konak et al, 2005). At the same time, these outliers, which occur differently according to the measurement plan, observation types and weights, are called leverage point effect in the robust statistic (Hekimoğlu, 2005). This situation is the most criticized and query aspect of the LS method. Both the LS and the LAV estimation are adversely affected by the leverage point effect.

On the other hand, normal distribution laws can be applied easily and successfully to LS results (Öztürk and Şerbetçi 1992). As a result of this feature; LSM methods are strengthened by the LS estimation method and integrated estimation methods called robust estimation methods are developed and implemented. If the measurements with sufficient degree of freedom are in normal distribution, the LAV, LMS and LS estimation magnitudes (sample means) are the same and their variances also exhibit asymptotically unbiased behavior (Dilaver et al., 1998; Konak and Dilaver, 1998).

The purpose of this paper is to perform experimental strain or robustness analysis using polyhedrons defined for any network point, by an appropriate estimation method. For this purpose, Affine Transformation is used as a mathematical model, and the strain tensors/components of symmetric and anti-symmetric characteristics are estimated by LAV, LMS and LS estimation methods separately. In the last step, an integrated solution algorithm is proposed by utilizing the useful properties of these methods.

\section{MATHEMATICAL METHOD}

Any surface strain model is written in the form of the Affine Transformation Model using deformation/velocity vectors at the neighbor network points where any station point is connected (Table 1a). Strain elements representing the surface are obtained accordingly to the objective functions of LAV, LMS or LS estimation (Niemeier, 2002)

If the strain elements tensor matrix (E) are arranged in the form of symmetric (S) and anti-symmetric (A) matrices, random strain rates can be obtained. If the symmetric (S) matrix is separated into eigenvalues and eigenvectors; the principal strain axes representing any polyhedron and the strain invariants (dilation, differential rotation, maximum shear strain) in any coordinate system are obtained (Table $1 \mathrm{~b}$ ). The non-diagonal element of the anti-symmetric matrix (A) is called the differential rotation strain (Vanicek et al., 1990; Berber, 2006; Yetkin, 2012; Küreç Nehbit, 2018). 
Table 1. Strain components and Mathematical Model

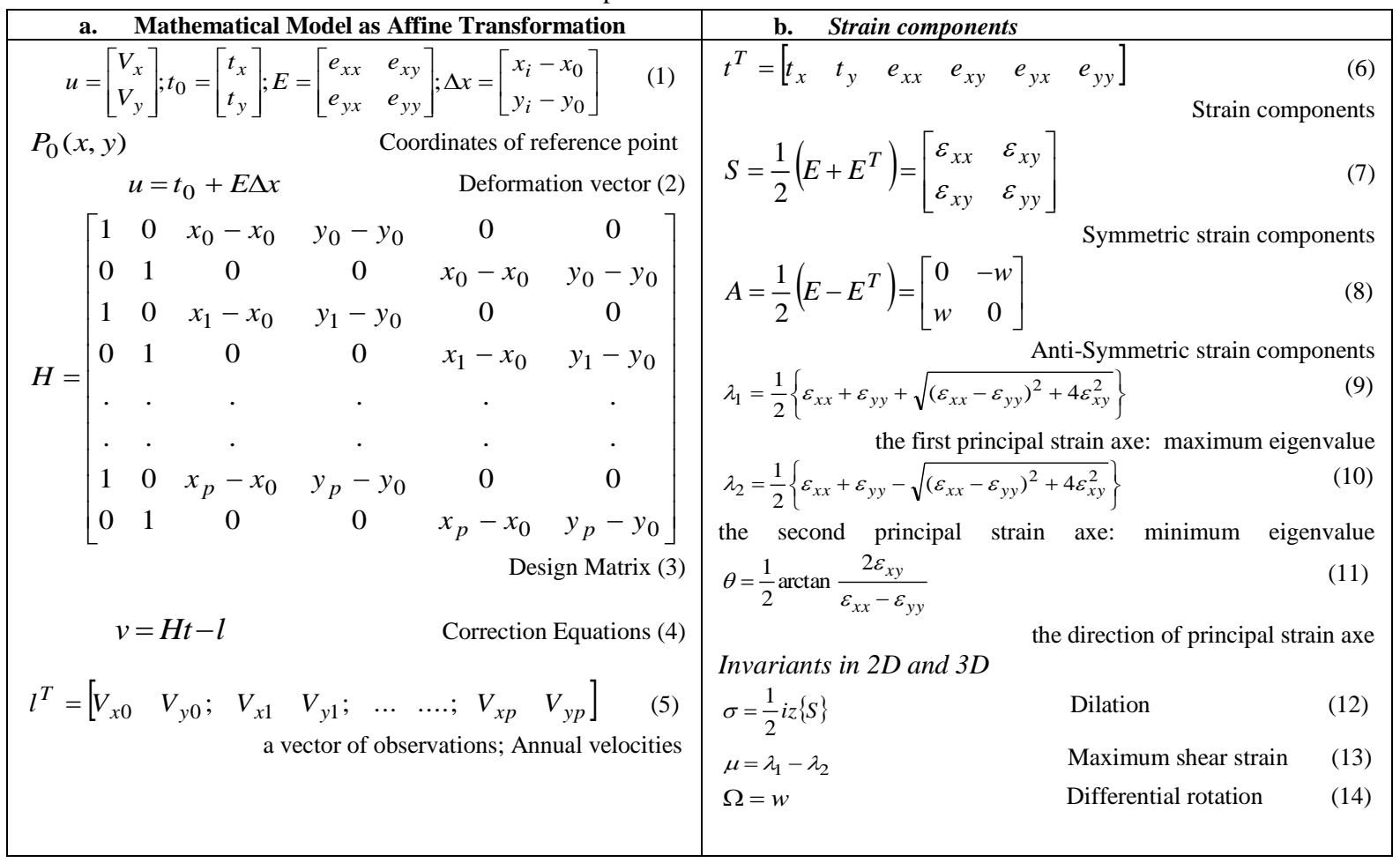

\section{ESTIMATION METHODS}

The LAV estimation method corresponds to the solution of the Affine Transformation problem in equation (4) with the inequality system described in Table 1a. This inequality system, called linear programming, can be solved by using Simplex Algorithms. In this solution method, for model parameters, there shouldn't be any sign constraint. In this case, the measurement corrections, having equal number to the number of unknown parameters, are equal to "zero". As a Maximum Likelihood Estimation (MLE), in this method the sum of absolute values of corrections is going to be minimal (Bektaş and Şişman, 2010). Thus, a special equation solution is obtained where the number of measurements is equal to the number of unknown (Table 2a).

In LAV method, it is aimed to localize the effect of the data which has abnormal distribution in the measurement sets and to minimize the sum of the absolute values of the corrections as much as possible. However, such a purpose function cannot always be guaranteed. In other words, in case there are error-free data in some subsets of measurements, LAV estimation is not an efficient solution. On the other hand, this estimation process can be used as an a priori approach/step to be able to determine random gross errors in the transformation problems. As a result of this situation; the LMS method is suggested as another MLE method to control the LAV method (Hekimoğlu, 2005; Niemeier, 2002).

In Regression and Transformation problems, measurements separated from the barycenter of network points or from geometric distribution of the observations called "Leverage Point Effect" are highly effective on the parameters. In this case, the leverage point effect can be explained as the spreading effect of the random errors in poor controllable observations onto the other observations. The LMS estimator can determine initially the most appropriate observation set purged of outliers. Therefore, it is recommended as an estimator to control the LAV estimation (Niemeier, 2002).

The LMS method is solved by an algorithm similar to the LAV method. For example; in affine transformation problem, the design matrices are composed form the $(\mathrm{u}+$ 2) transformation equation row, where $u$ is the number of unknowns and $q$ is the number of coordinate pairs. In this case, the different solution combinations $\left(\begin{array}{l}p \\ 4\end{array}\right)$ arise. The optimal solution is the least value of Median Squares in all of these combinations, as $\left(\Omega=\right.$ median $\left.\downarrow v_{i}^{2} \mid \Rightarrow \min .\right)$ (Table 2b).

LAV and LMS methods, which are called MLE methods, provide successful results when the distribution of measurements is well known. On the other hand, LS estimation method is an estimation type that gives minimum variance and unbiased results for the sets of measurement which are known to normal distribution at the beginning or not. In this case, LS method can be used as an estimation method to control the MLE (Table 2c).

As a result of LS aim-function, outliers in the observation set are able to disrupt the estimation values and also have a negative effect on other observations which have a normal distribution. This is the most criticized and questioned aspect of the LS method. However, in the LS method, the higher the numbers of abnormal observations are the more extend is the unit variance of model. This property of LS method allows for the localization and elimination of outliers in observations having gross-error using mathematicalstatistical methods (Öcalan 2019; Yıldırım and Şişman, 2019).

However, in strain analysis; the number of common control points is quite limited and, in this case, it is 
difficult to determine the abnormal observations (outliers). On the other hand, normal distribution laws can be applied easily and successfully to the LS results. As a result of this situation, taking advantage of the features of the LS squares estimation, integrated approaches/algorithms that can be controlled by LSM estimations can be developed (Table $2 \mathrm{~d}$ ).

Table 2. Estimation Methods for Strain Elements

\begin{tabular}{|c|c|}
\hline \multicolumn{2}{|c|}{ Strain Model: 2D Affine Transformation } \\
\hline The Least Absolute Value (LAV) Estimation & b. The Least Median Squares (LMS) Estimation \\
\hline $\begin{array}{l}\begin{array}{l}\Omega=\Sigma|v| \Rightarrow \min \\
H t-v \leq l\end{array} \\
\begin{aligned} H\left(t^{+}+t^{-}\right)-\left(v^{+}-v^{-}\right) \leq l \\
t^{+} \geq 0 ; t^{-} \geq 0 ; v^{+} \geq 0 ; v^{-} \geq 0\end{aligned} \\
\quad \text { Special Case } \\
\quad \text { The Number of Common control point } \mathrm{p}=3 \\
\begin{aligned} \Omega=\Sigma|v| \Rightarrow \min \equiv \min \left\{\Omega_{i} ; i=1,2, \ldots .\left(\begin{array}{l}p \\
3\end{array}\right)\right\} \\
(p=3 ; \quad n=2 * p=6 ; \quad u=6 ; \quad n=u)\end{aligned} \\
H_{i}^{-}=\left(H^{T} H\right)^{-1} H_{(u, u)}^{T} \\
t_{i}=H_{i}^{-} l\end{array}$ & $\begin{array}{l}\text { The Number of Common control point } \mathrm{p}=4 \\
\Omega=\text { median }\left|v_{i}^{2}\right| \Rightarrow \min \equiv \min \left\{\Omega_{i} ; i=1,2, \ldots .,\left(\begin{array}{l}p \\
4\end{array}\right)\right\} \\
(p=4 ; m=2 * p=8, ; u=6 ; \quad m>u) \\
H_{i}^{-}=\left(H^{T} H\right)^{-1} H_{(u, m)}^{T} \\
t_{i}=H_{i}^{-} l\end{array}$ \\
\hline $\begin{array}{l}\text { c. The Least Squares (LS) Estimation } \\
\end{array}$ & d. The Least Squares-Robust (LS-R) Estimation \\
\hline $\begin{array}{l}\text { The Number of Common control point } \mathrm{p}=\mathrm{p} \\
\Omega=v^{T} v \Rightarrow \min \\
\left(n=2^{*} p ; \quad u=6 ; \quad n>u\right) \\
H^{-1}=\left(H^{T} H\right)^{-1} H^{T} \\
t=H^{-1} l\end{array}$ & 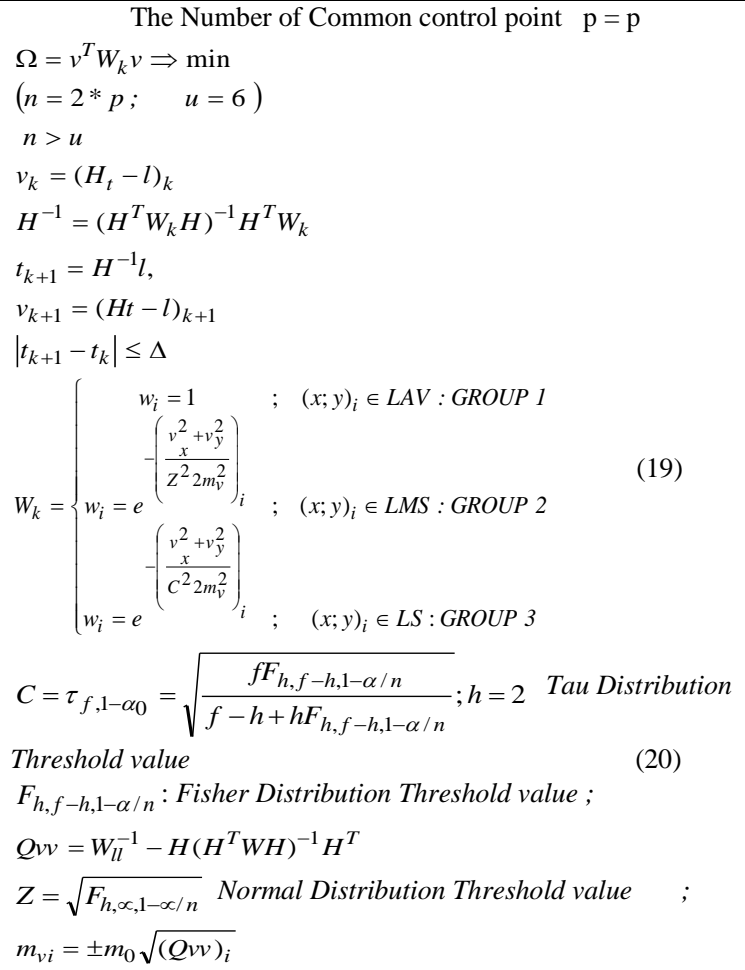 \\
\hline e. The Damped Least $\mathrm{S}$ & Iares (D-LS: Levenberg- Marquard,) \\
\hline$\Omega=v^{T} v+2 \vartheta\left(t^{T} t-t_{0}\right)^{2} \Rightarrow$ min Objective function & $t=\left(H^{T} H+\vartheta I\right)^{-1} H^{T} l$ Solution set \\
\hline
\end{tabular}




\subsection{Solution Algorithm}

The main purpose of this paper is to develop a feasible and usable solution algorithm for experimental strain or theoretical robustness analysis-processes using polyhedrons defined according to any network point. In this solution algorithm, LS estimation method is controlled by LSM methods and strengthened by a robust estimation method which we recommend in necessary and obligate situations. This solution algorithm can be summarized in five steps.

In the first step, by using the LAV estimation method which is to minimize the sum of absolute values of the corrections, a priori values of the strain components are estimated, for the polyhedron in any station point (Niemeier, 2002). With the help of LS estimation, the pair of common control points that provide the objective function and equal to the number of unknowns are classified as first group observations (Table 2a).

In the second step, by the LSM estimation method where the median square is minimum, the results of LAV estimation are controlled. In this step, the design matrices are composed to form the transformation equation row $(u+2)$, where $u$ is the number of unknowns and $\mathrm{q}$ is the number of coordinate pairs. The transformation unknowns are obtained. These results are compared with LAV solutions. In this comparison, the pair of common control points that provide the objective function and also aren't there in the first group are classified as second group observations (Table 2b).

In the third step, the LS estimation is used which minimizes the sum of squares of the corrections by using all the common control points for the polyhedron determined in each station point. In this step, the set of network points not included in the LAV and LMS estimation are classified as third control network points (Table 2c).

In the fourth step, the experimental strain invariants and their distribution on the network are compared. For example, if the comparison operations are based on a priori-robustness analysis, the location, direction and magnitude of the dilatations, maximum shear and rotation invariants can be questioned.

As a result of the LS estimation, observations not conforming to the distribution of corrections may occur. As this case, a fifth step, separately robust weighting functions are defined for observations disrupting the distribution in three different groups. In this regard, corrections and their cofactors obtained from LS estimation are used. However, the weights of the common control point's pairs determined by using the LAV estimation are not altered and these weights are saved as original weights. The robust weighting procedure occurs according to the threshold of the normal distribution for the second group's control points and according to the threshold of the Tau-distribution for the third group's control points (Table 2d). Under these conditions, LS-R estimation is performed by using all of the control points and the optimal strain invariants are obtained.

In the developed solution algorithm, the selected number of common control points for any polyhedron may be limited or insufficient in the outer zone points of the network. This leads to some rang or ill-conditioned defects in design matrix $\mathrm{H}$. Therefore, such a polyhedron can't be included in the stress/robustness analysis (Vanicek et al., 1996; Berber, 2006; Yetkin, 2012). On the other hand, Damped LS method (D-LS) is a useful common method for problems which lead to uncertainties in the solution set and their eigenvalues are equal to zero or too close (Canitez, 1996).

In the D-LS estimation, the constant $(\vartheta)$ added to the diagonal element of the normal equations is a damping constant which can be selected in the calculation accuracy and does not affect the solution results. These constants can be added to the eigenvalues of normal equations and consistent generalized inverses called "Lancsoz Inverse" are obtained (Table 2e).

Therefore, the D-LS method has a feature that can be successfully adapted to the LAV, LMS and LS methods especially at the outer zone points of the network especially.

LAV, LMS and LS solutions give identical results if the number of common control point pairs for any polyhedron is equal to the unknown number. In cases where the number of common controls point is equal to the number of points $(u+2)$, LMS and LS solutions are identical.

\section{NUMERICAL APPLICATION}

In this study, the annual velocities for Kocaeli University Permanent GPS Test Network (KOUSAGA) points are used for the numerical application data. The KOUSAGA network is established in the process of the Project of Monitoring of İzmit-Kocaeli Natural Gas Infrastructure (IZDOGAP) with the Geodetic Networks and Geographical Information Systems. This project is a scientific research project (Figure 1).

By evaluating the $30 \mathrm{sec}$ rinex data of this network points with GAMIT/GLOBK software, 3 years of regular coordinate and velocity area information of KOUSAGA network are obtained (Herring et al., 2015a and 2015b). The first group of these is selected from point of 10 IGS (NOT1, MATE, ORID, BUCU, ISTA, ANKR, TUBI, NICO, CRAO and ZECK). The second group is selected from point of 11 IGS (TEKR, BAND, BURS, ISTN, SLEE, IZMT, BILE, HEND, NAHA, BOLU and ZONG). KOUSAGA network covers İZDOGAP project network and is established to represent the velocity area of this network. KOUSAGA consist of 2 IGS (TUBI and ISTA) and 11 TUSAGA-Active (HEND, IZMT, ISTN, ZONG, BOLU, NAHA, BILE, BURS, BAND, TEKR and SLEE) stations.

The observation plan of the KOUSAGA network is designed with the aid of delaunay triangulation (Küreç Nehbit, 2018). For the strain calculations, the coordinate and velocity information defined in the ITRF 2008 reference system is used. Strain surfaces are determined as regular polyhedrons formed according to the observation plan designed for every station point. Strain components and symmetrical strain ratio tensors are obtained by LAV, LMS and LS estimation methods. 


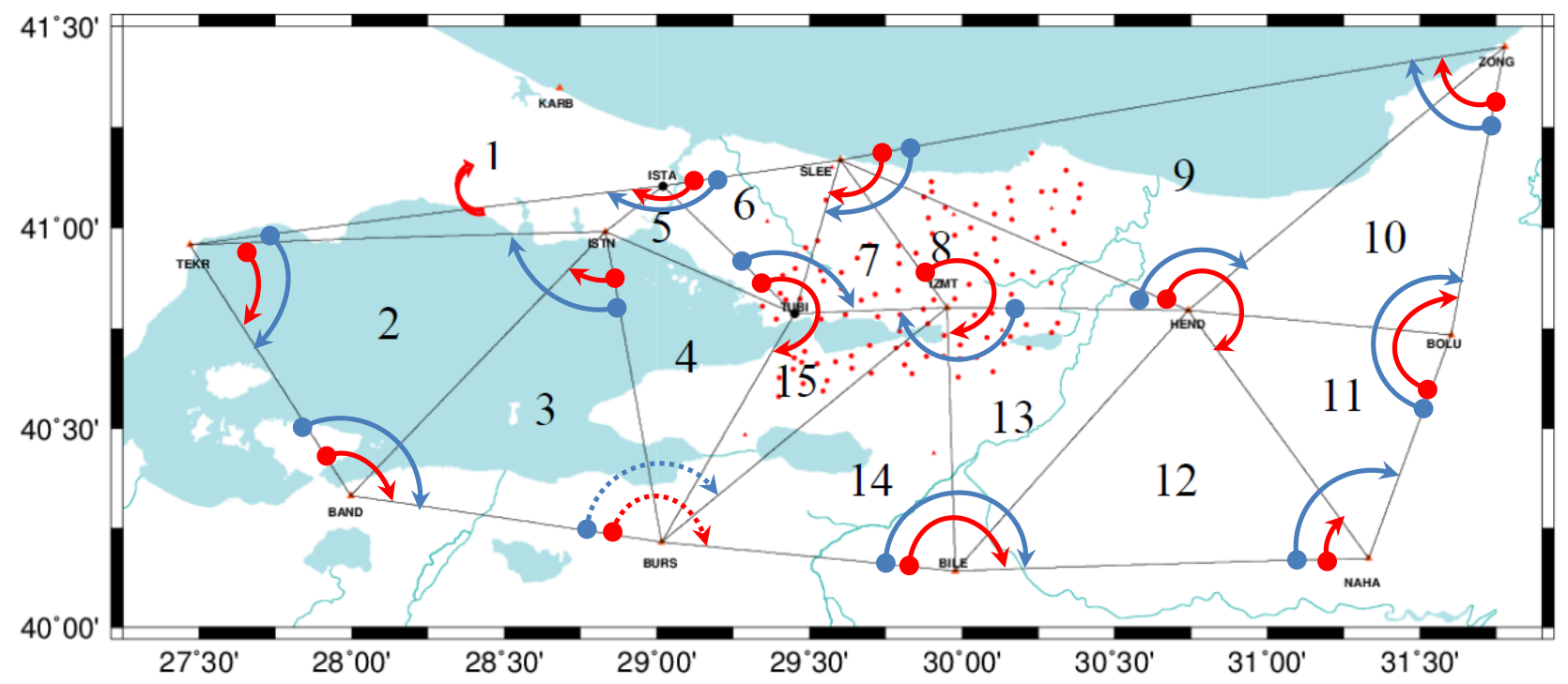

Figure 1. Kocaeli University Permanent GPS Test Network (KOUSAGA) and ranking direction of selected common points for the Strain model (Red: Red: according to LAV solution, Blue: according to LMS solution, Dashed line: barycenter point of network which is eliminated in both methods, $1,2, \ldots .14,15$ : number of triangles)

Experimental results are compared in terms of optimal deformation surfaces represented by any of the polyhedrons. According to these results;

- According to the results of LAV and LMS, the common points entering the set of strain model are scattered as to cover the widest possible area over the surface of any polyhedron, and these points are located around the barycenter of the polyhedron in both methods.

- As can be seen in equation (3), the design matrix $\mathrm{H}$ related to the surface of any polyhedron strain is constructed using the shifted coordinate differences according to this surface's barycenter point. As a result of this situation, according to the results of the LAV estimation method, barycenter points of polyhedrons could often not be included in the optimal common point combinations (Table 3 ).

- In the LMS estimator, common points that do not contribute positively to the geometric shape have been excluded. In LMS estimation, the barycenter point of any polyhedron is included in all combinations, except for the BURS point, which is located at the same line approximately with the BAND and BILE points (Figure 1 , Table 3).

When the results are compared in terms of object functions and estimation types, in polyhedrons consisting of four (4) common network points, the results of LAV and LMS estimation remain the same. Theoretically, in the case of normal distribution of observations, the median value is expected to be the smallest and the standard deviation is to be the largest.

- According to both biased median and absolute error and unbiased standard deviation, this ranking is provided except the points of ZONG, BOLU, NAHA, BAND and TEKR. Mentioned points are the outer zone points at both ends of the KOUSAGA network (Tables 4, 5 and 6).

Table 3. A Comparison of Polyhedron Gravity Centers

\begin{tabular}{|c|c|c|c|c|c|c|}
\hline \multicolumn{7}{|c|}{ Inner zone network points } \\
\hline Barycenter & $p$ & $\begin{array}{c}\text { LAV } \\
\text { First group observation }\end{array}$ & $\begin{array}{c}\text { LMS } \\
\text { Second group observation } \\
\end{array}$ & $\begin{array}{l}\text { Third group } \\
\text { observation }\end{array}$ & Polyhedron & $\begin{array}{l}\text { Excluded } \\
\text { triangles }\end{array}$ \\
\hline HEND: 2009 & 7 & SLEE, ZONG, NAHA & HEND, IZMT, SLEE, ZONG & BOLU, BILE (S) & Area with Widest Angle & $12-13$ \\
\hline IZMT: 2007 & 6 & SLEE, HEND, BILE & IZMT, HEND, BURS, TUBI & ---- & Entire area & -- \\
\hline TUBI: 1006 & 6 & ISTA, IZMT, BURS & TUBI, ISTA, SLEE, IZMT & ISTN (K) & Area with Widest Angle & 4 \\
\hline ISTN: 2004 & 6 & ISTN, BURS, BAND & ISTN, BURS, BAND, TEKR & ISTA, TUBI (N) & Area with Widest Angle & $1-5$ \\
\hline \multicolumn{7}{|c|}{ Outer zone network points } \\
\hline Barycenter & $p$ & $\begin{array}{c}\text { LAV } \\
\text { First group observation }\end{array}$ & $\begin{array}{c}\text { LMS } \\
\text { Second group observation } \\
\end{array}$ & $\begin{array}{l}\text { Third group } \\
\text { observation }\end{array}$ & Polyhedron & $\begin{array}{l}\text { Excluded } \\
\text { triangles }\end{array}$ \\
\hline ZONG: 2012 & 4 & ZONG, BOLU, SLEE & ZONG, BOLU, HEND, SLEE & --- & Entire area & -- \\
\hline BOLU: 2011 & 4 & NAHA, HEND, ZONG & BOLU, NAHA, HEND, ZONG & -..- & Entire area & --- \\
\hline NAHA: 2010 & 4 & NAHA, BILE, HEND & NAHA, BILE, HEND, BOLU & --- & Entire area & --- \\
\hline BILE: 2008 & 5 & BURS, HEND, NAHA & BILE, BURS, HEND, NAHA & IZMT (N) & Entire area & --- \\
\hline BURS: 2003 & 6 & BAND, TUBI, BILE & BAND, ISTN, TUBI, BILE & BURS & Entire area & --- \\
\hline BAND: 2002 & 4 & TEKR, ISTN, BURS & BAND, TEKR, ISTN, BURS & ---- & Entire area & --- \\
\hline TEKR: 2001 & 4 & TEKR, ISTN, BAND & TEKR, ISTA, ISTN, BAND & $-\cdots$ & Entire area & --- \\
\hline ISTA: 1005 & 5 & SLEE, TUBI, TEKR & ISTA, SLEE, TUBI, TEKR & ISTN (S) & Entire area & --- \\
\hline SLEE: 2006 & 6 & ZONG, HEND, TUBI & SLEE, ZONG, HEND, TUBI & IZMT, ISTA (S) & Area with Widest Angle & 6 \\
\hline \multicolumn{7}{|c|}{$(N)$ : in North of Barycenter } \\
\hline
\end{tabular}


Table 4. Strain Elements and Results for LS and LS-R Solutions

\begin{tabular}{|c|c|c|c|c|c|c|c|c|c|c|}
\hline \multirow[b]{2}{*}{$\begin{array}{c}\text { KOUSAGA } \\
\text { Net Points }\end{array}$} & \multirow[b]{2}{*}{$\mathbf{p}$} & \multirow[b]{2}{*}{ 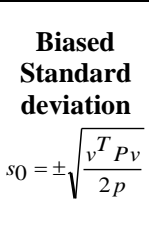 } & \multirow[b]{2}{*}{$\begin{array}{c}\begin{array}{c}\text { Unbiased } \\
\text { Standard } \\
\text { deviation }\end{array} \\
m_{0}= \pm \sqrt{\frac{v^{T} P v}{2 p-6}}\end{array}$} & \multirow[b]{2}{*}{$\begin{array}{c}\mathbf{L S} \\
\Omega=v^{T} P v \Rightarrow \min \end{array}$} & \multicolumn{3}{|c|}{ Strain Components } & \multicolumn{3}{|c|}{ Principal Strain Invariants } \\
\hline & & & & & $\begin{array}{c}\lambda_{1} \\
\text { (the first } \\
\text { principal } \\
\text { axis: } \\
\text { maximum } \\
\text { eigenvalue) }\end{array}$ & $\begin{array}{c}\lambda_{2} \\
\text { (the second } \\
\text { principal axis: } \\
\text { maximum } \\
\text { eigenvalue) }\end{array}$ & $\begin{array}{c}\boldsymbol{\theta} \\
\text { (the } \\
\text { direction of } \\
\text { principal } \\
\text { axis) }\end{array}$ & $\begin{array}{c}\sigma \\
\text { (Dilation) }\end{array}$ & $\begin{array}{c}\mu \\
\text { (Maximum } \\
\text { shear } \\
\text { strain) }\end{array}$ & $\begin{array}{c}\Omega \\
\text { (Differential } \\
\text { rotation ) }\end{array}$ \\
\hline HEND & 7 & 0,00146 & 0,00193 & $2,99.10^{-5}$ & $8,19.10^{-8}$ & $-1,02.10^{-7}$ & $6,62 \cdot 10^{-1}$ & $-9,82.10^{-9}$ & $1,83.10^{-7}$ & $8,25.10^{-8}$ \\
\hline IZMT & 6 & 0,00110 & 0,00156 & $1,47.10^{-5}$ & $1,32 \cdot 10^{-7}$ & $-9,70.10^{-8}$ & $7,37.10^{-1}$ & $1,75.10^{-8}$ & $2,29.10^{-7}$ & $1,10.10^{-7}$ \\
\hline TUBI & 6 & 0,00127 & 0,00180 & $1,95.10^{-5}$ & $1,38.10^{-7}$ & $-8,78.10^{-8}$ & $7,46.10^{-1}$ & $2,51.10^{-8}$ & $2,26.10^{-7}$ & $1,11.10^{-7}$ \\
\hline ISTN & 6 & 0,00109 & 0,00154 & $1,42.10^{-5}$ & $1,53.10^{-7}$ & $-1,07.10^{-7}$ & $6,94.10^{-1}$ & $2,27.10^{-8}$ & $2,60.10^{-7}$ & $1,13 \cdot 10^{-7}$ \\
\hline$\overline{\mathrm{ZONG}}$ & 4 & 0,00111 & 0,00222 & $9,83.10^{-6}$ & $4,98.10^{-8}$ & $-1,00.10^{-7}$ & $7,27.10^{-1}$ & $-2,52 \cdot 10^{-8}$ & $1,50.10^{-7}$ & $6,87.10^{-8}$ \\
\hline BOLU & 4 & 0,00097 & 0,00193 & $7,48.10^{-6}$ & $6,52 \cdot 10^{-8}$ & $-1,27.10^{-7}$ & $5,86.10^{-1}$ & $-3,10.10^{-8}$ & $1,92 \cdot 10^{-7}$ & $6,51 \cdot 10^{-8}$ \\
\hline NAHA & 4 & 0,00118 & 0,00235 & $1,11.10^{-5}$ & $1,15.10^{-7}$ & $-1,10.10^{-7}$ & $6,69 \cdot 10^{-1}$ & $2,73.10^{-9}$ & $2,25.10^{-7}$ & $8,82 \cdot 10^{-8}$ \\
\hline BILE & 5 & 0,00069 & 0,00109 & $4,77.10^{-6}$ & $1,39.10^{-7}$ & $-1,15.10^{-7}$ & $7,41.10^{-1}$ & $1,17.10^{-8}$ & $2,54.10^{-7}$ & $1,17.10^{-7}$ \\
\hline BURS & 6 & 0,00051 & 0,00072 & $3,12.10^{-6}$ & $1,68.10^{-7}$ & $-1,07.10^{-7}$ & $7,17.10^{-1}$ & $3,07.10^{-8}$ & $2,75.10^{-7}$ & $1,21.10^{-7}$ \\
\hline BAND & 4 & 0,00008 & 0,00016 & $4,99.10^{-8}$ & $1,76.10^{-7}$ & $-1,12.10^{-7}$ & $6,73.10^{-1}$ & $3,19.10^{-8}$ & $2,89.10^{-7}$ & $1,16.10^{-7}$ \\
\hline TEKR & 4 & 0,00099 & 0,00199 & $7,90.10^{-6}$ & $1,48.10^{-7}$ & $-1,15.10^{-7}$ & $6,58.10^{-1}$ & $1,68.10^{-8}$ & $2,63 \cdot 10^{-7}$ & $1,15.10^{-7}$ \\
\hline ISTA & 5 & 0,00064 & 0,00102 & $4,13.10^{-6}$ & $6,74.10^{-8}$ & $-6,52 \cdot 10^{-8}$ & $7,19.10^{-1}$ & $1,11.10^{-9}$ & $1,33.10^{-7}$ & $5,55.10^{-8}$ \\
\hline SLEE & 6 & 0,00042 & 0,00059 & $2,11.10^{-6}$ & $4,88.10^{-8}$ & $-6,01.10^{-8}$ & $6,71.10^{-1}$ & $-5,65.10^{-9}$ & $1,09.10^{-7}$ & $5,47.10^{-8}$ \\
\hline
\end{tabular}

Table 5. Strain Elements and Results for LAV

\begin{tabular}{|c|c|c|c|c|c|c|c|c|c|c|}
\hline \multirow[b]{2}{*}{$\begin{array}{c}\text { KOUSAGA } \\
\text { Net Points }\end{array}$} & \multirow[b]{2}{*}{$\mathbf{p}$} & \multirow[b]{2}{*}{$\begin{array}{c}\text { Biased } \\
\text { Standard } \\
\text { deviation } \\
s_{0}= \pm \frac{\sum|v|}{2 p}\end{array}$} & \multirow[b]{2}{*}{ 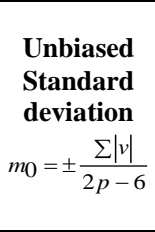 } & \multirow[b]{2}{*}{$\begin{array}{c}\text { LMS } \\
\Omega=\Sigma|v| \Rightarrow \min \end{array}$} & \multicolumn{3}{|c|}{ Strain Components } & \multicolumn{3}{|c|}{ Principal Strain Invariants } \\
\hline & & & & & $\begin{array}{c}\lambda_{1} \\
\text { (the first } \\
\text { principal } \\
\text { axis: } \\
\text { maximum } \\
\text { eigenvalue) } \\
\end{array}$ & $\begin{array}{c}\lambda_{2} \\
\text { (the second } \\
\text { principal axis: } \\
\text { maximum } \\
\text { eigenvalue) }\end{array}$ & $\begin{array}{c}\theta \\
\text { (the direction } \\
\text { of principal } \\
\text { axis) }\end{array}$ & $\begin{array}{c}\sigma \\
\text { (Dilation) }\end{array}$ & $\begin{array}{c}\mu \\
\text { (Maximum } \\
\text { shear } \\
\text { strain) }\end{array}$ & $\begin{array}{c}\Omega \\
\text { (Differential } \\
\text { rotation ) }\end{array}$ \\
\hline HEND & 7 & 0,00102 & 0,00179 & 0,0143 & $6,58 \cdot 10^{-8}$ & $-9,15 \cdot 10^{-8}$ & $6,68 \cdot 10^{-1}$ & $-1,28.10^{-8}$ & $1,57.10^{-7}$ & $8,08.10^{-8}$ \\
\hline IZMT & 6 & 0,00076 & 0,00152 & 0,0091 & $1,19.10^{-7}$ & $-8,89.10^{-8}$ & $7,70.10^{-1}$ & $1,50.10^{-8}$ & $2,08.10^{-7}$ & $1,08.10^{-7}$ \\
\hline TUBI & 6 & 0,00093 & 0,00185 & 0,0111 & $1,64 \cdot 10^{-7}$ & $-8,76.10^{-8}$ & $-7,62.10^{-1}$ & $3,84 \cdot 10^{-8}$ & $2,52.10^{-7}$ & $1,10.10^{-7}$ \\
\hline ISTN & 6 & 0,00078 & 0,00157 & 0,0094 & $1,77.10^{-7}$ & $-1,10.10^{-7}$ & $6,77.10^{-1}$ & $3,33 \cdot 10^{-8}$ & $2,87.10^{-7}$ & $1,16.10^{-7}$ \\
\hline ZONG & 4 & 0,00074 & 0,00295 & 0,0059 & $4,78.10^{-8}$ & $-1,17.10^{-7}$ & $-7,69.10^{-1}$ & $-3,47.10^{-8}$ & $1,65 \cdot 10^{-7}$ & $7,90.10^{-8}$ \\
\hline BOLU & 4 & 0,00045 & 0,00180 & 0,0036 & $5,59 \cdot 10^{-8}$ & $-1,17.10^{-7}$ & $5,65 \cdot 10^{-1}$ & $-3,07.10^{-8}$ & $1,73 \cdot 10^{-7}$ & $7,54.10^{-8}$ \\
\hline NAHA & 4 & 0,00094 & 0,00375 & 0,0075 & $1,18.10^{-7}$ & $-1,12.10^{-7}$ & $7,49 \cdot 10^{-1}$ & $3,22.10^{-9}$ & $2,30 \cdot 10^{-7}$ & $1,07.10^{-7}$ \\
\hline BILE & 5 & 0,00055 & $\mathbf{0 , 0 0 1 3 8}$ & 0,0055 & $1,32 \cdot 10^{-7}$ & $-1,12.10^{-7}$ & $7,63 \cdot 10^{-1}$ & $1,00 \cdot 10^{-8}$ & $2,44 \cdot 10^{-7}$ & $1,10 \cdot 10^{-7}$ \\
\hline BURS & 6 & 0,00040 & 0,00080 & 0,0048 & $1,69.10^{-7}$ & $-1,14.10^{-7}$ & $7,29.10^{-1}$ & $2,77.10^{-8}$ & $2,83 \cdot 10^{-7}$ & $1,20.10^{-7}$ \\
\hline BAND & 4 & 0,00005 & 0,00020 & 0,0004 & $1,74.10^{-7}$ & $-1,12.10^{-7}$ & $6,69 \cdot 10^{-1}$ & $3,13 \cdot 10^{-8}$ & $2,86.10^{-7}$ & $1,15 \cdot 10^{-7}$ \\
\hline TEKR & 4 & 0,00065 & 0,00260 & 0,0052 & $1,34 \cdot 10^{-7}$ & $-1,16.10^{-7}$ & $6,42 \cdot 10^{-1}$ & $9,09 \cdot 10^{-9}$ & $2,50 \cdot 10^{-7}$ & $1,16.10^{-7}$ \\
\hline ISTA & 5 & 0,00038 & 0,00095 & 0,0038 & $7,47 \cdot 10^{-8}$ & $-6,64.10^{-8}$ & $7,04.10^{-1}$ & $4,12 \cdot 10^{-9}$ & $1,41.10^{-7}$ & $5,90.10^{-8}$ \\
\hline SLEE & 6 & 0,00030 & 0,00060 & 0,0036 & $5,33 \cdot 10^{-8}$ & $-5,97.10^{-8}$ & $6,38 \cdot 10^{-1}$ & $-3,19.10^{-9}$ & $1,13 \cdot 10^{-7}$ & $5,94.10^{-8}$ \\
\hline
\end{tabular}

Table 6. Strain Elements and Results for LMS Solutions

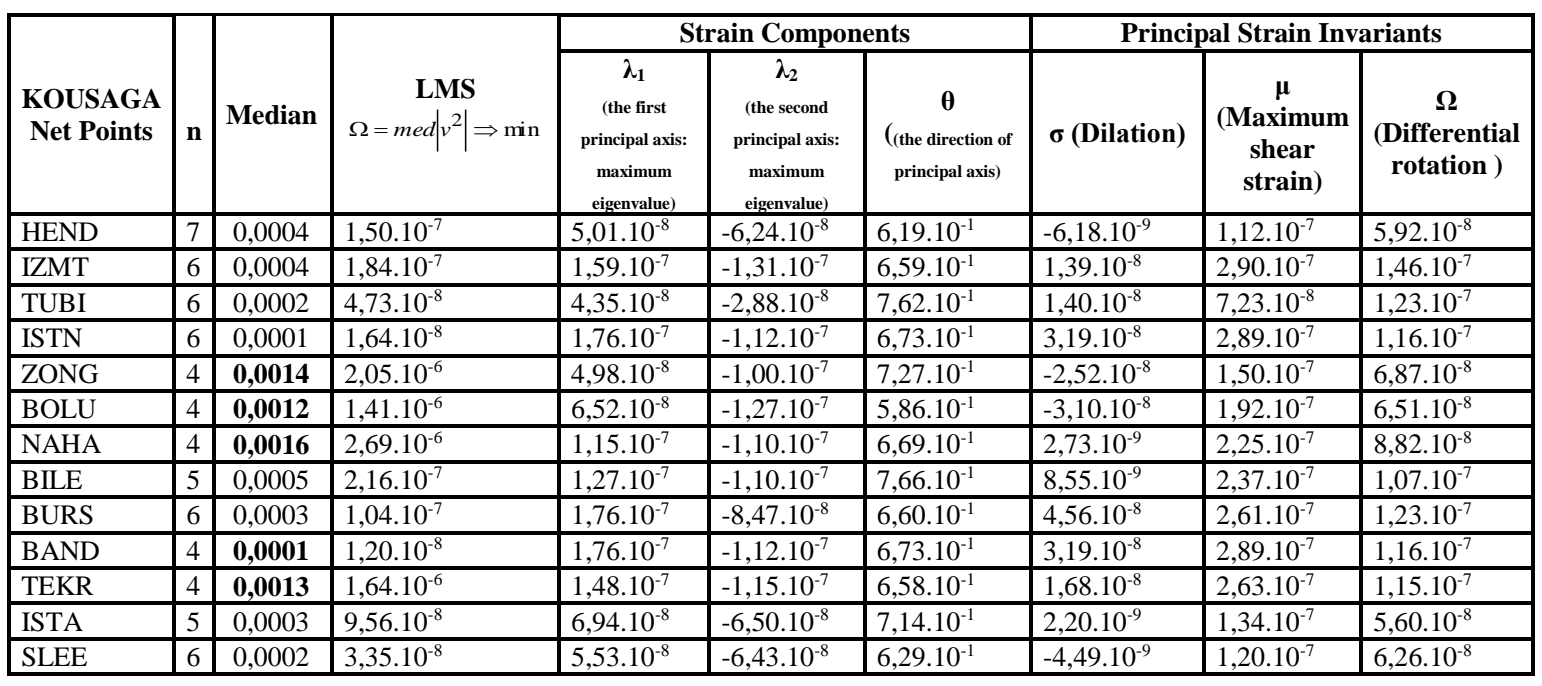


- $\quad$ According to the values computed by using degrees of freedom as a mixed unbiased comparison, estimation values of LAV unbiased absolute error are obtained as smaller than LS unbiased error estimation values except for HEND, IZMT, BOLU and ISTA points (Tables 4 and 5).

Principal strain invariants obtained by LAV, LMS and LS methods are compared by drawing surface maps (Figures 3, 4 and 5) and the values obtained are summarized as tables (Tables $\mathbf{4 , 5}$ and 6). In this study, differential rotation maps are emphasized as an interesting sample. These maps and table data are examined; the surface maps of LAV and LS estimations are generally similar. Significant changes according to LMS estimation are observed at the inner zone points of the network. This is due to the fact that the number of common pairs in the outer zone of the network is equal to or very close to the number of strain parameters. Therefore, all three estimators are produced similar results in the outer zone.

On the other hand, the behavior of the LMS estimation is clearly recognizable at the inner zone points of the network (TUBI and IZMT). In the LMS estimation, the points representing the polyhedron according to the TUBI point are selected from the northern part of the polyhedron. The points representing the polyhedron according to the IZMT point are selected from the southern part of the polyhedron (Figure 1). The northern part of the TUBI polyhedron belongs to the EURASIA Plate and the southern part of the IZMT polyhedron belongs to the ANADOLU Plate. We would like to emphasize here as authors, the main purpose of this paper is not to question plate movements, but to examine the behavior of LAV, LMS and LS estimators. However, these estimation results are quite interesting. In other words; the distribution and number of these points on the polyhedrons are the most optimal solutions which provide the objective function of the LMS estimation. The results mentioned here should be considered as the leverage point and at the same time the common effects of observations which do not conform to the annual velocity distribution of the common points. Similar results are observed in the behaviors of the principal strain components (Figure 2 and 3 ).

Strain surfaces according to the dilatation maps are generally similar. However, due to the lever point effect, the Maximum Shear Strain Map of the LMS estimator is exhibited a different distribution according to the maps of other estimators (Figure 4 and 5).

In this study; according to the LS estimation results, there has not arisen any observation group that passed the threshold value of the normal distribution or Taudistribution and excluded from the common point sets of LAV or LMS. Therefore, these have not conformed to the normal distribution. For this reason, the results of LS and LS-R estimation are identical (Tables 3,4 and 5 and Figures 2, 3 and 4).

\section{CONCLUSION}

When numerical results and graphs are analyzed together; LMS estimation shows that besides the velocities to related the network points, the barycenter point is also very effective in eliminating the leverage point effect.
During the computing of the strain components for any network point, the reference point selected for a polyhedron is determined as the barycenter of polyhedron. In this case, due to the objective function, LAV estimation method uses the common network points representing velocity information consistent with the barycenter. Therefore, the estimated values are the best approximate values representing the strain components. According to our experimental results, a polyhedron or deformation surface determined by LMS estimation is a shape improved and supported by barycenter point of any surface determined by use of the LAV estimation.

As a result, in the geodetic network, during the interpreting of the deformations points with experimental strain or robustness analyzes, the common network points and velocity information determined by the LMS and LAV method should be preserved as much as possible. For this reason, if the LS estimation method is used, the surface properties estimated by LMS and LAV methods should be considered and interpreted together. 

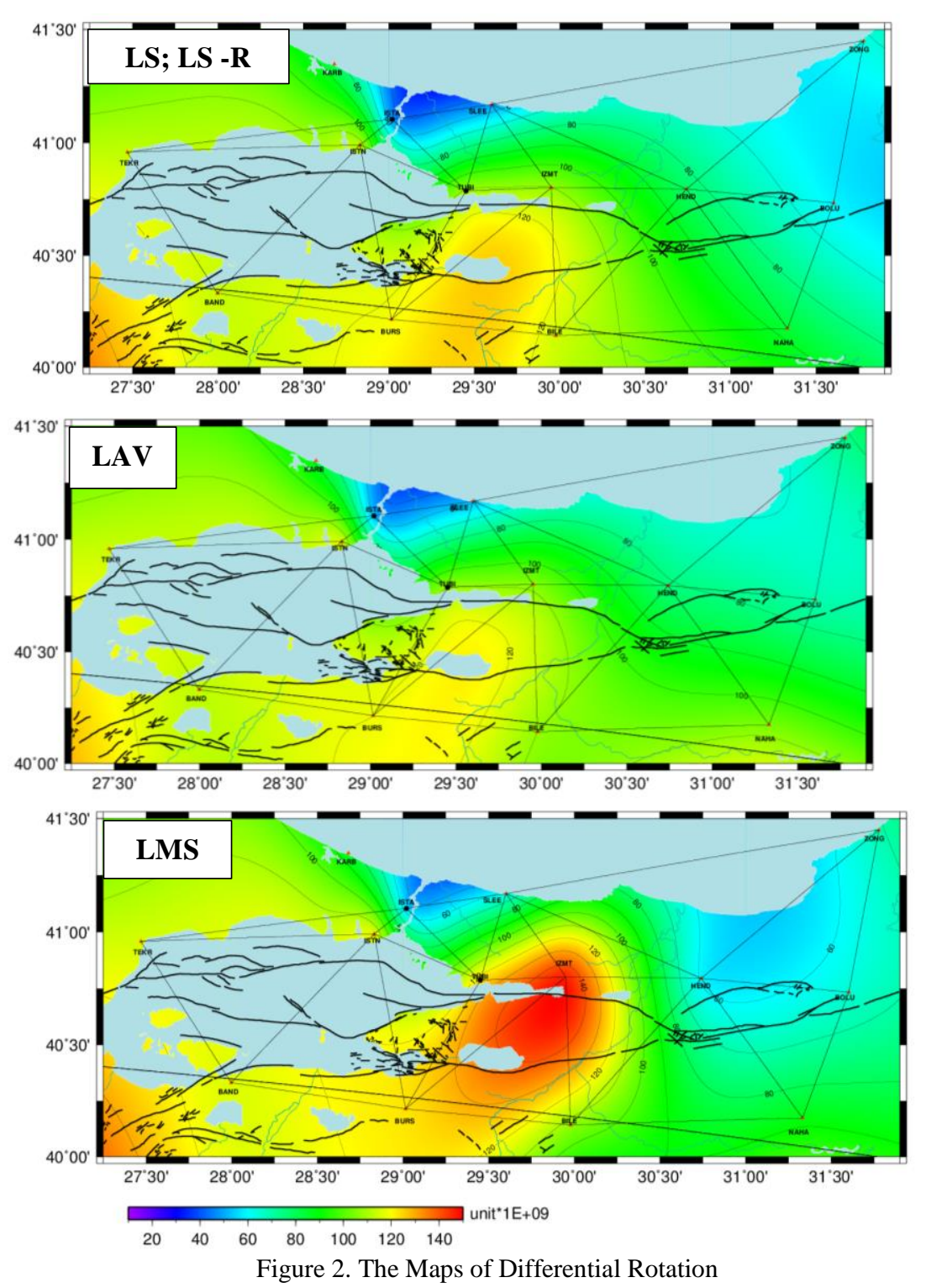
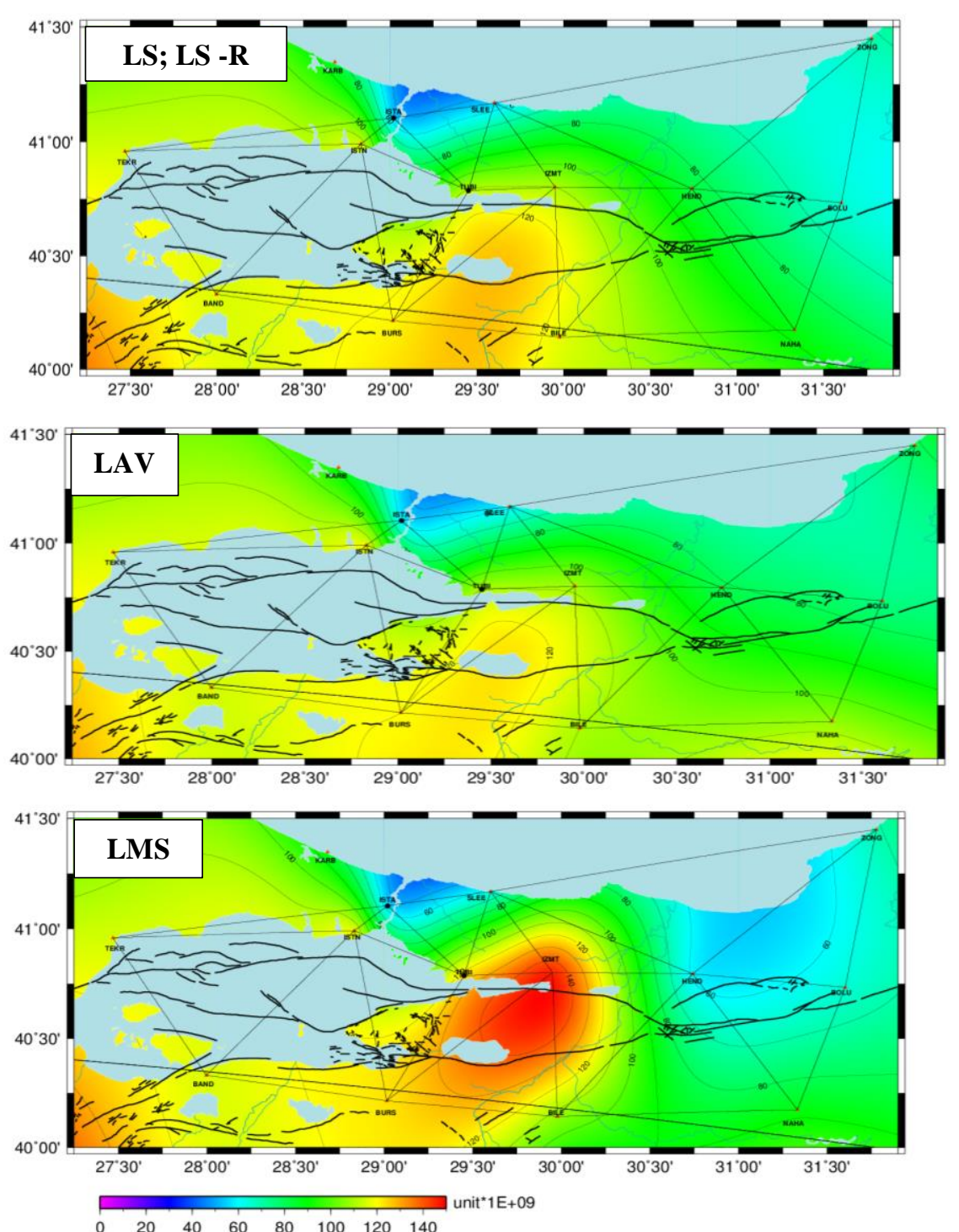

Figure 3. The Maps of The First Principal Strain Axe: Maximum Eigenvector $\left(\lambda_{\max }\right)$ 

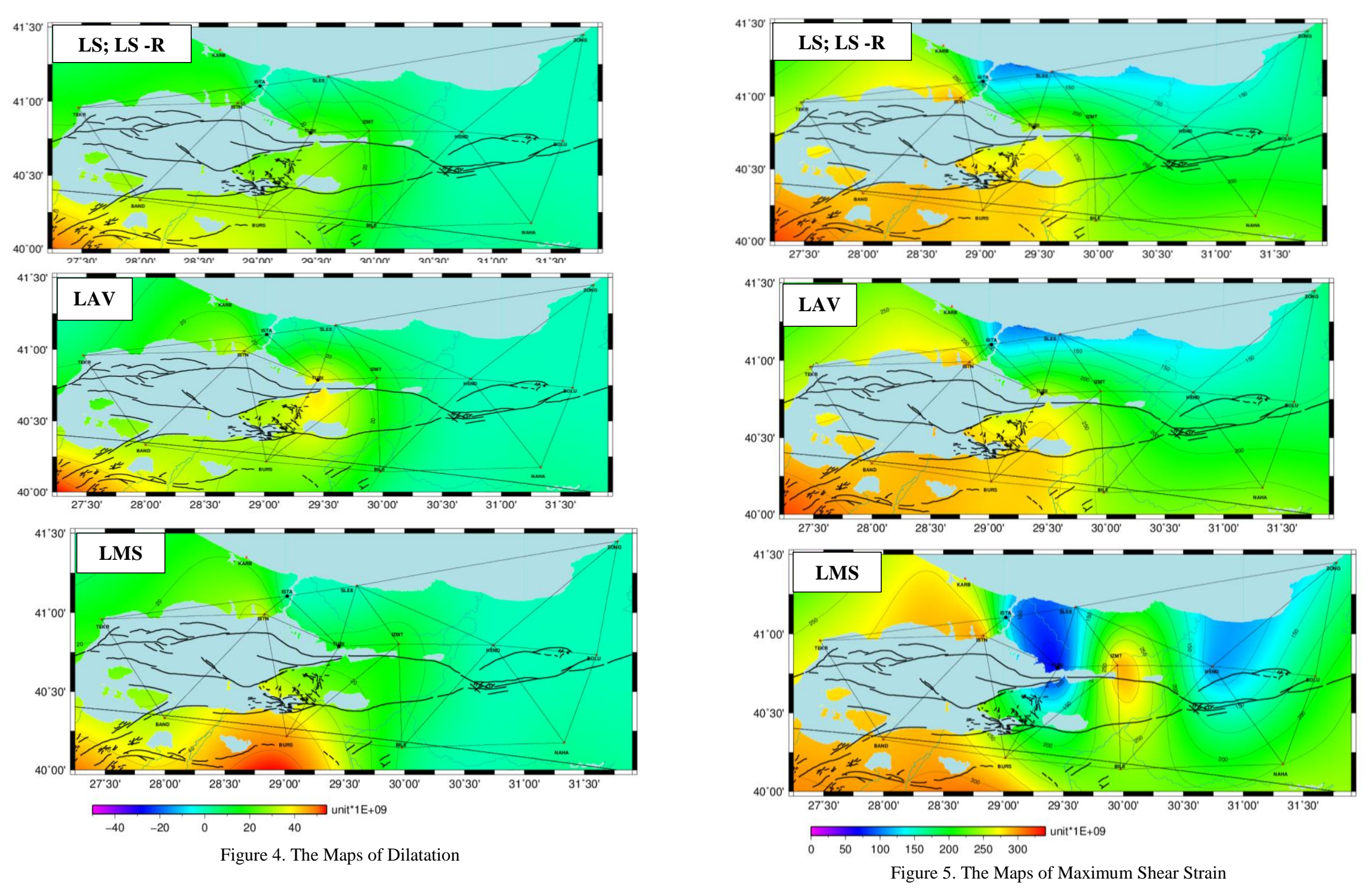


\section{REFERENCES}

Berber M. (2006), Robustness Analysis of Geodetic Networks Technical Report, University of New Brunswick, New Brunswick, Canada, 121 ss.

Bektaş S., Şişman Y. (2010) The Comparison of L1 ve L2norm minimization methods, International, Journal of Physical Sciences, 5 (11), 1721-1727.

Canıtez N., (1997), Jeofizikte Modelleme, Literatür Yayıncıllk, İstanbul, Türkiye, 368 ss.

Dilaver A, Konak H., Çepni M. S., (1998), Jeodezik Ağlarda Uyuşumsuz Ölçülerin Yerelleştirilmesinde Kullanılan Yöntemlerin Davranışları, Harita ve Kadastro Mühendisliği Dergisi, Ankara, 84 (1), 17-34.

Hekimoğlu, Ş. (2005), Increasing Reliability of the Tests for Outliers Whose Magnitude is Small, Survey Review, 38 (298), 274-285

Herring T. A., King R. W., Floyd M. A., McClusky S. C., GAMIT Reference Manual, http://wwwgpsg.mit.edu/ simon/gtgk/GAMIT_Ref.pdf, 2015.

Herring T. A., King R. W., Floyd M. A., McClusky S. C., Introduction to GAMIT/ GLOBK, http://wwwgpsg.mit.edu/ simon/gtgk/Intro_GG.pdf, 2015.

Konak H., Dilaver A (1998), Jeodezik Ăglarda Uyuşumsuz Ölçülerin Yerelleştirilmesinde Kullanılan Yöntemlerin Davranışları -II, -Fuzzy Logic (Bulanık Mantık) Yaklaşımı, Harita ve Kadastro Mühendisliği Dergisi, Ankara, 85(1), 91-109.
Konak, H., Dilaver, A., Öztürk, E., (2005), Effects of Observation Plan and Precision on the Duration of Outliers Detection and Fuzzy Logic: A Real Network Application, Survey Review, (38) 298, 331-341.

Niemeier W., (2002), Ausgleichungsrechnung, Walter de Gruyter Kehrbuch, Berlin, Germany - New York, USA, 407 ss.

Öcalan T., (2019) Investigation Common Points in 2D Transformation Problem, International Journal of Engineering and Geosciences, 4 (2), 58-62.

Öztürk E., Şerbetçi M, (1992), Dengeleme Hesabı Cilt III, KTÜ Yayınları, 2. Baskı, Yayın No: 144/40, Trabzon, Türkiye, 558 ss.

Küreç Nehbit P., (2018), GPS/GNSS Ağları için Sürekli Bir Gerinim İzleme ve Kalite Değerlendirme Stratejisi, Doktora Tezi, Kocaeli Üniversitesi, Kocaeli, Türkiye.

Vanicek P., Krakiwsky E. J., Craymer M. R. Gao Y., Ong P. S. (1990), Robustness Analysis, Technical Report, University of New Brunswick, New Brunswick, Canada.

Yetkin M., (2012), GNSS Gözlemlerinin Robust Kestirimi ve Robustluk Analizi Yöntemleriyle Değerlendirilmesi Üzerine Bir İnceleme, Selçuk Üniversitesi, Konya, Türkiye.

Yildırım. Ü. K., Şişman Y. (2019) The Deformation Analysis Using Hypothesis Tests, International, Journal of Engineering and Geosciences, 4 (2), 88-93. 